\title{
Fuel Consumption Impacts of Auto Roof Racks
}

\author{
Yuche Chen $^{* a}$, Alan Meier ${ }^{\mathrm{b}}$ \\ ${ }^{a}$ National Renewable Energy Laboratory, 15013 Denver West Parkway, Golden, CO 80401, \\ Yuche.Chen@nrel.gov \\ bawrence Berkeley National Laboratory, 1 Cyclotron Road, MS 90R2000, Berkeley, CA 94720
}

\begin{abstract}
The after-market roof rack is one of the most common components attached to a vehicle for carrying over-sized items, such as bicycles and skis. It is important to understand these racks'fuel consumption impacts on both individual vehicles and the national fleet because they are widely used.We estimate the national fuel consumption impacts of roof racks using a bottom-up approach.
\end{abstract} Our model incorporates real-world data and vehicle stock informationto enable assessing fuel consumption impacts for several categories of vehicles, rack configurations, and usage conditions.In addition, the model draws on two new data-gathering techniques, on-line forums and crowd-sourcing. The results show that nationwide, roof racks are responsible for $0.8 \%$ oflight duty vehicle fuel consumption in 2015 , corresponding to100million gallonsof gasoline per year. Sensitivity analyses show that results are most sensitive to the fraction of vehicles with installed roof racks but carrying no equipment. The aerodynamic efficiency of typical roof racks can be greatly improved and reduce individual vehicle fuel consumption; however, government policies to minimize extensive driving with empty racks - if successful—could save more fuel nationally. Keywords: Roof racks, fuel consumption impacts, energy modeling 


\section{Introduction}

Passenger cars and passenger trucksare major petroleum consumers and contributors of greenhouse gas (GHG) and criteria pollutants emissions in many countries around the world (Oak Ridge National Laboratory, 2014; Environmental Protection Agency, 2013; Wang et al., 2009; International Energy Agency, 2009; Chen and Borken-Kleefeld, 2014). Any strategiesseeking toreducefuel consumption (FC) and emissions of the light duty vehicle (LDV) ${ }^{1}$ fleet must involve technologies and policies addressing these vehicles (Barter, et al., 2012; Kyle and Kim, 2011; Leighty, et al., 2012; Westbrook, et al., 2014; Wu and Aliprantis, 2013; Borken-Kleefeld and Chen, 2015). In the United States (U.S,), the federal andstate governments have implemented regulations to reduce LDVfuel consumption and emissions (Al-Alawi and Bradley, 2014; Kirby, 1992; Goldberg, 1998; Morrison and Chen, 2011; Chen and Fan, 2013; Chen and Fan, 2014). Because of these regulations, the average fuel efficiency of thenew fleet of passenger cars and passenger truckshas increased from 28.7and 21.3 mile per gallon (MPG) in 2000 to 35.5 and 25.3 MPG in 2013, respectively (Bureau of Transportation Statistics, 2015). Similar trends in new vehicle fuel efficiencyare observed in the European Union and other countries (Global Fuel Economy Initiative, 2012). The officialfuel consumptioninformation for a specific vehicle model istypically determined by driving the vehicleaccording to pre-determined cycles, such as the Federal Test Procedure, Highway Fuel Economy Test, US06, SC03, etc., on a chassis dynamometer (US EPA, 2006). Therefore, the measurements do not reflectafter-marketaccessories (towing trailer, roof rack, etc.) or alternative components (low rolling resistance tires, etc.), which could result in unrepresentative fuel consumptioninformationin real-world usage conditions. These omissions will also result ininaccurate estimates of national fuel consumption (Hughes, 1991; Thomas, et al.,

\footnotetext{
${ }^{1}$ Light Duty Vehicle means a light duty truck or light duty vehicle, as such terms are defined under section 216(7) of the Clean Air Act (42 U.S.C. 7550(7)), having a gross vehicle weight rating of 8,500 pounds or less, before any after-market conversion to alternative fuel operation.
} 
2014).

The roof rack is one of the most common and popularaccessorieson U.S. vehicles (The Reynolds and Reynolds Company, 2014). A roof rack can beattached to a vehicle roof for occasional carrying of bicycles, skis, boxes, etc. Major brands of roof racks in the United States are Barrecrafters, Saris, Thule, and Yakima.The configurations of roof racksvary depending on the need but they always increase aerodynamic drag and causevehicles to expend additional energy to achieve desired speeds.Aerodynamic drag $(D)$ depends on four factors: projected frontal area $(A)$; the drag coefficient $\left(C_{D}\right)$; vehicle speed $(V)$; air density $(\rho)$, and is expressed as shown in Equation 1 (Hucho, 1998).

$$
D=\frac{1}{2} C_{D} \times \rho \times V^{2} \times A(1)
$$

Based on the above equation, installation of a roof rackcan increase aerodynamic drag by increasingboth the drag coefficient $\left(C_{D}\right)$ and the projected frontal area $(A)$. Previous studies foundthat,for a car moving at $100 \mathrm{~km} / \mathrm{h}$, aerodynamic drag typically accounts for $75 \sim 80 \%$ of the total resistance, which is directly related to vehicle FC (Hucho, 1998; Juhala, 2014). Therefore, a roof rack (and the loads installed on it) will lead to a significantFC penalty on an individual vehicle. These individual vehicle impacts extend to the national fleet.Since leisure travel and spending are projected to rise in the United States (US Travel Association, 2015), roof rack usage will most likely rise, too. This off-test fuel consumption, combined with widespread usage of roof racks, suggests a potential gap in our understanding of on-road fuel consumption. More detailed information can guide policies and regulations regarding roof racks for the purpose of reducing national fuel consumption and GHG emissions. Fuel consumption can also be reduced by improving the aerodynamic features of theracks. The technical potential from reduced drag appears to be large. One manufacturer (Whisbar, 2011) measured the aerodynamic drag forces of 
12 different rack designs in a wind tunnel. It was found that the most slippery model had roughly $1 / 10$ of the drag of the least aerodynamic model.

There has been relatively little published research on the fuel consumption penalties of roof racks. Two studies in 1985 and 1986 investigated FC impacts of roof-mounted light bars on police vehicles (Raub, 1985; Hansen and Blakenship, 1986). The roof-mounted light bar isa different application but has similar aerodynamics impacts. Adding roof-mounted light bars increased fuel consumption $7.1 \% \sim 12.7 \%$ when the vehicles weredriven a constant $55 \mathrm{mph}$ and $7.5 \%$ on overall driving miles (e.g., mixed speeds). Lenner (1998) investigated on-road impacts of roof racks for a 1992 Volvo 940 midsize sedan. The vehicle was equipped with an unloaded roof rack anddriven at $43.5 \mathrm{mph}, 49.7 \mathrm{mph}$ and $55.9 \mathrm{mph}$. Fuel consumption increased $2.6 \%, 2 \%$ and $1.1 \%$ compared with a clean roof. When the roof rack was loaded with a ski box, fuel consumption increased 10\%, $11 \%$ and $12.3 \%$ compared with the clean-roof conditions. The results were physically counter-intuitive in that the unloaded roof rack FC penalties actually decreasedat higher speeds. Nevertheless, this was one of the first studies ofFC impacts of roof racks and it illustrated measurement uncertainties in on-road studies. In contrast, Chowdhury et al. (2012) measured drag forces of passenger caradd-onsthrough a series of wind tunnel tests. At high driving speeds $(>80 \mathrm{~km} / \mathrm{h}$ ), the unloadedand loaded roof rack (carrying a ladder) resulted in 10\% 22\% and 13\% 28\% increases in aerodynamic drag depending on cross-wind effects and speeds. The drag forces can be translated into $7.5 \% \sim 17.6 \%$ and $10 \% \sim 22.4 \%$ increases in vehicle motion resistance and similarFC penalties. Chowdhury et al. estimated the combined FC penalty of installing all add-ons, but did not estimate the FC penalty for each add-on, such as a roof rack, towing trailer, etc. Thomas et al. (2014) adopted a similar methodology as Lenner (1998), but focused on evaluating FC penalties of different vehicle add-ons and modifications (i.e. low-pressure tires, open windows, roof top and 
hitch-mounted cargo, and trailer) through coast-down and dynamometer tests. The tests were conducted on popular vehicles. A rooftop cargo box significantly increasedthe vehicle'sFC, but the magnitudes varied depending on the vehicle typeand driving cycles. When a rooftop cargo box was installed on a Corollasedan, FC increased $8.8 \%$ and $20.8 \%$ on city and highway driving cycles, respectively. For a Ford Explorer SUV, the FC penalties were $2.5 \%$ and $6.2 \%$ on the two driving cycles. The Thomas et al. (2014) study did not consider the FC penalty of an unloaded roof rack and the authors didnot extrapolate the vehicle-level FC impacts to the national fleet. Other studies explored roof racks' impacts on design, noise, and forces (Jawad, et al., 2000; Lee, et al., 2002; Karbon and Dietschi, 2005; Senthooran, et al., 2007; Mandadapu et al., 2011).

In summary, previous studies using laboratory or on-road testing methods have explored roof rack FC penalties at a single-vehicle level, but they did not estimate national impacts on LDV fuel consumption. A national perspective is still needed to justify policy actions.

To fill this gap, weundertooka bottom-up study of national FC impacts of roof racks. The methodologyintegrates real-world experiments, field surveys, and a vehicle stock model to assess theroof rackFC impactson the national LDV fleet. This approachdifferentiates roof rack FC impacts by vehicle type, driving situation (such as highway, urban driving) and utilization pattern (weekday and weekend). In addition, the methodology can be applied to estimate nationwide FC penalties of other LDV add-ons. Thisstudy's precision is inherentlylimited by the available data regarding FC penalties of specific rack configurations and the wide range of vehicle body styles, but the results are nevertheless meaningful and can inform policy-making. Furthermore, the methodology easily accommodates incremental improvements in input data as they become available. 
The rest of the paper is organized as follows: methodology and data are discussed in section 2 . The results and sensitivity analyses are detailed in section 3 . The conclusion and policy implications are presented in section 4.

\section{Methodology}

The purpose of this study is to create a methodology to estimate the incremental LDV fuel consumption caused by installation and usage of roof racks in the United States. Conventional modeling approaches and data are not appropriate here. For example, the sales of roof racks do not necessarily correlate with their installation and usage. The estimate is handicapped by lack of data at both the vehicle and national levels, including limited vehicle-level roof rack FC penalty information, lack of rack usage data, and absence of a suitable energy inventory model.Our approach addresses these challenges by collecting primary data through novel methods and building an energy inventory model tailored for the study. The methodological framework is shown inFigure 1.

\section{[Insert Figure 1 here]}

We first define the following index and set to be used in the study.

\begin{tabular}{l|l}
\hline Set name & Description \\
\hline $\mathrm{Y}$ & Set of analysis year $\{2015, \ldots 2040\}$, indexed by $y$ \\
\hline $\mathrm{I}$ & Set of all vehicle types, indexed by $i$ \\
\hline $\mathrm{C}$ & Set of driving conditions $\{$ Highway, Non-highway $\}$, indexed by $c$ \\
\hline $\mathrm{R}$ & Set of roof rack configurations as discussed in section 2.1 , indexed by $r$ \\
\hline $\mathrm{D}$ & Set of day types \{weekday, weekend $\},$ indexed by $d$ \\
\hline Variable & Description \\
\hline$V \_F C_{-} P_{i, c, r}^{y}$ & $\begin{array}{l}\text { Vehicle-level FC penalty by vehicle type } i, \text { driving condition } c, \text { and roof } \\
\text { rack configuration } r \text { in each analysis year } y .\end{array}$ \\
\hline Freq $q_{c, r}$ & $\begin{array}{l}\text { Roof rack usage rates by driving condition } c, \text { and roof rack } \\
\text { configuration } r \text { in each analysis year } y .\end{array}$ \\
\hline$V M T_{i}^{y}$ & Aggregated fleet VMT by vehicle type $i$ and year $y$. \\
\hline$V M T \_S p l i t_{c, d}$ & VMY split among road condition and day of week. \\
\hline
\end{tabular}




\begin{tabular}{c|l}
\hline$A_{-} F C_{-} R_{c, i}^{y}$ & $\begin{array}{l}\text { Average FC (Gallon / Mile) for vehicle type } i, \text { on driving condition } c, \text { at } \\
\text { year } y .\end{array}$ \\
\hline$T_{-} F C_{o}^{y}$ & Total LDV fleet FC in year ywithout considering roof rack FC impact \\
\hline$T_{-} F C_{n}^{y}$ & Total LDV fleet FC in year yincluding roof rack FC impact \\
\hline
\end{tabular}

We firstestimate vehicle-level roof rack FC penalties, $A_{-} F C_{-} R_{c, i}^{y}$ based on consumer-reported data (compiled from on-line forums) and limited test data from existing studies. In our baseline analysis, we assume the penalties do not change over time, but in later scenarios, we vary the penalty over time given assumptions of changes in rack design, government policies, etc.

Next, we estimate roof rack usage rates, $r e q_{c, r}$. These rates were based on nationwide highway video surveys conducted by the authors or workers recruited through Amazon Mechanical Turk ${ }^{2}$. Note that rack usage rates were assumed to be the same for all vehicle types because we do not have enough observations to confidently estimate the differences.

Third, an energy inventory model was established to project the nationwide LDV roof rack FC penalty in current and future years. The model includes vehicle-level roof rack FC penalties, rack usage rates, vehicle stock, and vehicle miles travelled (VMT) through 2040. The national-level LDV fleet FC without considering roof racksat year $y, T F C_{o}^{y}$, is calculated by disaggregating VMT by vehicle type, road condition (highway and non-highway) and day of week (weekdays and weekends), and then multiplied by the associated vehicle FC rates (in units of Gallon / Mile), shown as follows.

$T F C_{o}^{y}=\sum_{i \in I, y \in Y} \sum_{c \in C, d \in D} V M T_{i}^{y} * V M T_{-} S_{p l i t}{ }_{c, d} * A_{-} F C_{-} R_{c, i}^{y}$

\footnotetext{
${ }^{2}$ Amazon Mechanical Turk is a on-line marketplace for tasks that requires human intelligence. It gives businesses access to a diverse, on-demand, scalable workforce and gives Workers a selection of thousands of tasks to complete whenever they choose.
} 
The national FC is the sum of two parts. The first part represents the FC for vehicles without roof rack impacts, which is similar to the calculation process of $T F C_{o}^{y}$ with exclusion of roof rack-related VMT. The second part represents the FC of vehicles with racks installed. These vehicles' FC rates will be increased by the roof rack FC penalties, shown below.

$$
\begin{gathered}
T F C_{n}^{y}=\sum_{i \in I, y \in Y} \sum_{c \in D, d \in D, r \in R}\left\{V M T_{i}^{y} * V M T_{-} \text {Split }_{c, d} *\left(1-\text { Freq }_{c, r}\right) * A_{-} F C_{-} R_{c, i}^{y}+V M T_{i}^{y}\right. \\
\left.* V M T_{-} \text {Split }_{c, d} * \text { Freq }_{c, r} * A_{-} F C_{-} R_{c, i}^{y} *\left(1+V_{-} F C_{-} P_{i, c, r}^{y}\right)\right\}
\end{gathered}
$$

Finally, the roof rack FC penalty at the national level at year yis calculated by:

$F C$ Penalty ${ }^{y}=\frac{T F C_{n}^{y}-T F C_{o}^{y}}{T F C_{o}^{y}} \times 100 \%$

In the remainder of this section, we discuss the details of the framework,starting with the categorization of roof racks.

\subsection{Roof RackCategorization}

We dividedthe many configurations of roof racks into three categories. These categories reflect their gross aerodynamic impacts. The categories are illustrated in Figure 2 and defined as follows:

[Insert Figure 2 here]

1) Bare roof or roof with built-in rails.Built-in rails run front to back, along the sides of a vehicle's roof. In most cases, the built-in rails are installed by the vehicle manufacturer and are part of a package. We assume this type of rack does not significantly influence vehicle FC. To be sure, built-in roof rails alter the vehicle frontal area and therefore can potentially increase aerodynamic drag force. However, the change in vehicle frontal shape is usually 
small, in part because car manufacturers have been continuously improving the aerodynamics of built-in rails (Carr, 1976; Howard, 1986; Karbon and Dietschi, 2005; Kelly and Holcombe, 1964). In any event, the aerodynamic impacts of these racks are often already captured in fuel economy tests because they are part of many packages for new vehicles.

2) Unloaded cross roof racks.In this configuration, crosspieces are present to adapt the pre-existing roof rack to the specific application, such as carrying bicycles or skis. Additional hardware may be present to facilitate attachment. By "unloaded", we mean the hardware is present for a specific application but no bicycles, skis, etc. are actually being carried. Consumers typically install crosspieces after they purchase the vehicles. Several previous studies have identified FC impacts of such roof racks or similar rooftop attachmentsin this configuration (Hansen and Blakenship, 1986; Lenner, 1998; Raub, 1985).

3) Loaded cross roof racks. In this configuration, bicycles, skis or other equipment are actually on the roof rack and being transported. Previous studies have found large FC penaltiesin this configuration, especially at higher speeds(Lenner, 1998; Thomas et al., 2014). This configuration covers a wide range of aerodynamic resistances and fuel impacts. For example, this configuration includes a bicycle rack with one, two, or three bicycles, a ski rack with snow boards or skis, and a luggage rack. It is not feasible to further differentiatethis configuration due to lack of reliable data sources and the complexity of the problem.

\subsection{Roof Rack Fuel Consumption Impact at the Vehicle Level}

We utilized both consumer-reported and laboratory/on-road tested data to estimate roof rack FC penalties at the vehicle level. The FC penalties are expressed in relative terms (i.e. percentage 
increase in FC compared with the no-rack condition). Hence, when available data were reported in absolutechanges, we converted the results to relative changes. Consumer-reported datawere collected through searching on-line forums. Car-owners often reported and discussed their observations of FC penalties on their vehicles after theyinstalled racks. These drivers typically reported make/model of vehicles, recording date and time, road type, average driving speed, and FC penalties due to roof racks (see Supporting Information (SI) for reference). These self-reported data have obvious uncertainties, but these uncertainties are offset by the large number of measurements and wide variety of vehicles. For these reasons, these data can complement the laboratory or controlled on-road test data for more accurate estimates of fuel penalties.

The factors considered in the FC penalty calculation are rack configuration (unloaded/loaded cross roof rack), driving condition (highway, non-highway roads) and vehicle type (passenger car, passenger truck). There is an inherent uncertainty associated with this simple classification scheme. For example, items with different shapes can be loaded on a roof rack, vehicles can have different body styles and powertrain combinations,and driving patterns may differ. But the focus of this study is to provide a framework to quantitatively analyze roof rack FC penalties at a national level. We evaluated several scenarios in order to better understand the uncertainties described earlier.These are described below.

Unloaded racks on vehicles traveling at slower speeds. This situation corresponds to cars with empty racks driving around cities. For unloaded cross roof rack FC impacts on non-highway roads, no lab or on-road test data are available. Most consumer-reporteddata suggest no FC penalty for this type of configuration. Therefore, we assume $0 \%$ FC penalty due to unloaded cross roof rackson vehicles (passenger car, passenger truck) driving on non-highway roads. 
Loaded racks on vehicles traveling at slower speeds. This situation corresponds to cars transporting bicycles or skis driving around cities. No consumer-reported data are available for loaded cross roof rack FC impacts on urban roads. Only two previous studiesexaminedFC penalties of racks or similar roof-mounted itemsin non-highway drivinglocations. After a series of driving tests, a $7.5 \% \mathrm{FC}$ increase was observed for a police vehicle with roof-mounted lights compared with the same vehicle with a bare roof (Raub, 1985). Thomas et al. (2014) reported an $8 \%$ FC increase for a passenger car and $2.4 \%$ for a passenger truck driving the Federal Test Procedure (FTP) driving cycle. The FTP driving cycle was adopted as the city fuel economy test by EPA (EPA, 2006). In this study, we use the FC penalties for unloaded racks in non-highway driving conditions developed by Thomas et al. (2014), that is, $8 \%$ for passenger cars and $2.4 \%$ for passenger trucks.

Loaded racks on vehicles traveling at highway speeds. Data from on-line forums are concentrated in this scenario. About 70\% (18 observations out of 26) of consumer-reported data estimated loaded cross roof rack FC penalties between $20 \%$ and $30 \%$. Theseobservations seem to match results from Thomas et al. (2014) i.e., 24.8\% FC increase at $70 \mathrm{mph}$ constant-speed highway driving for passenger cars. Thomas et al. also reportedan $11.7 \%$ FC penalty for a passenger truck under the same conditions. Lenner (1998) found fuel consumption increased 12.3\% for a sedan with a roof rack and ski box travelling at $55.9 \mathrm{mph}$. An extrapolation of Lenner's result from 55.9 mph to $70 \mathrm{mph}$, gives a FC increaseofabout $20 \%$. This is close to other studies as well as consumer-reported data. We adopted $24.8 \%$ as the FC impacts for passenger cars and $11.7 \%$ for passenger trucks driving on highways. These values from Thomas et al. (2014) are the most recent and based on the most comprehensivestudy. 
Empty racks on vehicles driven at high speeds.About 84\% (26 out of 31) of consumer measurements reported FC penalties due to unloaded cross roof rack between $5 \%$ and $15 \%$. These results are not consistent with lab tests. One possible explanation for the discrepancy is that most drivers reported FC penalties in terms of MPG and they usually rounded the number up to the next integer. This reporting behavior potentially over-estimates the penalties. Two earlier studies found $1.1 \% \sim 2.6 \% \mathrm{FC}$ increases for a sedan travelling at $43.5 \sim 55.9 \mathrm{mph}$ with an unloaded cross roof rack (Lenner, 1998) and 6.6\% 11.3\% increase for a police patrol vehicle travelling at $55 \mathrm{mph}$ with different configurations of bar lights (Raub, 1985). Lenner (1998) showed that, when vehicle speedswere increased from $43.5 \mathrm{mph}$ to $55.9 \mathrm{mph}$, the FC penalties actually declined from $2.6 \%$ to $1.1 \%$. This inconsistency might be explained by the fact that fuel consumption and aerodynamic resistance of the rack do not increase at the same rate with speed.In our analysis, we assumed a $1.1 \%$ FC penalty for passenger cars with unloaded cross racks because this is a test-based result and is more relevant to our study. For passenger trucks, we applied the ratio between the two vehicle types from Thomas et al., that is, $11.7 \% / 24.8 \%$, to $1.1 \%$ and obtained $0.5 \%$ as the FC impact for passenger trucks during highway driving. These assumptions (for cars and trucks) are conservative because fuel impacts could be closer to consumer measurements.

\subsection{Highway Video Surveysto DetermineRoof Rack UsageBehavior}

We undertook field surveys and collected available traffic camera videos to estimate real-world roof rack utilization. The videos mainly come from two sources: national highway monitoring videos, and private videos taken by authors or individualsthrough “Amazon Mechanical Turk”. In selecting traffic observation locations, we sought to cover many US metropolitan areas and to captureboth weekday and weekend conditions. Figure 3 presents the locations, number of vehicles recorded and weekday (yellow) or weekend (purple) and other information about each video 
sample. Each video recorded about 20 to 330 passing vehicles. We counted the vehicles with each type of roof rack configuration and tabulated the shares as discussed in section 2.1.

[Insert Figure 3 here]

The shares of vehicles with unloaded and loaded racksrange between 1.5\% 4.5\%, and $0.2 \% \sim 1.5 \%$ (see SI for reference). We aggregated all samples into a national average. The nationalaveragesof vehicles with cross roof racks are $3.0 \%$ on weekdays, and $2.5 \%$ on weekends. For vehicles with loaded cross roof racks, the average number is $0.5 \%$ on weekdays and $0.9 \%$ on weekends.Higher percentages of vehicles with loaded roof racks were observed during weekendscompared with weekdays; this isconsistent with the expectation that people transport more recreational equipment during weekends. These values were used to estimate national roof rack FC impacts. Note that the usage data are not differentiated by road type because the sample sizeswere not large enough to make confident inferences. Our work, however, demonstrates that larger sample sizes could be acquired quickly and inexpensively. Since the focus of this study is to demonstrate a methodology, we used the above data and conducted sensitivity analyses to understand the uncertainty.

\subsection{Input Data}

Inputs for our studycame fromprimary and secondary data sources described above. Other input datawere obtained fromthe Annual Energy Outlook 2015 (EIA, 2015), the Bureau of Transportation Statistics (Bureau of Transportation Statistics, 2015), anddefault values from EPA's Motor Vehicle Emission Simulator (Environmental Protection Agency, 2009).

Two types of vehicles were considered, passenger cars and passenger trucks. Within each vehicle type, several powertrains (such as gasoline vehicles, different types of electric vehicles, hydrogen 
fuel cell vehicles)are included. These categories are consistent with definitionsin the 2015 Annual Energy Outlook (or AEO) (EIA, 2015). The total US LDV fleet VMT is based on AEO 2015 reference case. The AEO reference case disaggregates VMT by vehicle technology type for each year from 2015 to 2040(EIA, 2009). These were also used.The VMT distributions, broken down by geography (highway, non-highway roads) and time (weekdays and weekends) are obtained fromMOVES national default values (Environmental Protection Agency, 2009). The average FCper distance for each powertrainfrom2015 to 2040 comes from Annual Energy Outlook 2015 (EIA, 2015). MOVES default values as well as other VMT and fuel consumption data are used to calculate fuel consumption per distance on highway and non-highway roads (Bureau of Transportation Statistics, 2015; Environmental Protection Agency, 2009; ORNL, 2014). The roof rack vehicle-level FC impacts and utilization patterns are based on existing literature, website searches and field surveys as described previously (see base case definition in Table 1).

\section{Results}

\subsection{Roof Rack Fuel Consumption Penalty in Base Case}

Based on the model and input data describedabove, we estimatethe US nationwide FC penalty due to roof rack usage. Figure 4shows the roof rack FC penalty relative to total US annual transportation FC (left axis) and in actual gasoline gallon equivalent (GGE) (right axis). Roof racks increased national fuelconsumptionbyabout $0.81 \%$ in 2015 . The penaltyrises to $0.84 \%$ in 2040. The fractioninitially decreasesfrom $0.81 \%$ in 2015 to $0.78 \%$ around year 2018 and remains constantbetween 2018 and 2025. After 2025, the fraction increases again. This U-curve is causedby modeling assumptions regarding VMT and vehicle mix. Roof rack FC penalties for passenger cars are (relatively) higher thanthose for passenger trucks. When passenger carsare responsible for a largershare of distance travelled (compared to passenger trucks), the LDV fleet 
rack FC penalties relative to total transportation FC will be increasing, and vice-versa. The AEO (2015) predicts that total VMT for passenger cars willdecrease and reach a minimum around 2024; after thatit will climb until 2040. This trajectory matches the trend of roof rack FC penalties perfectly. The actual quantities of fuel consumed due to roof racksgradually decline, starting from 107 million to 90 million gasoline gallons equivalent in 2040. This decline is a consequence of long-term reductions in LDV fleet consumption assumed in the model (AEO, 2015).

[Insert Figure 4 here]

The results shown in per mile format are not sensitive to different mixes of advanced technology vehicles in the fleet because the vehicle-level roof rack FC penalty is defined as a relative term (i.e., \% more fuel consumed due to use of racks). In fact, the absolute size of the fuel penalty will decline when more energy efficient vehicles enter the fleet.

\subsection{Sensitivity Analysis of Parameters Related toRoof Racks}

As discussed in the methodology section, there exist significant uncertainties in roof rack usage patterns and vehicle-level FC penalties. We performed sensitivity analyses to understand the variation of roof rack FC penaltieswith changing input parameters. Here, vehicle-level roof rack FC penalties and usage pattern parameters were increased $20 \%$ in each scenario. We show only the positive change results (see Figure 5) because the absolute values do not change for $20 \%$ increase or decrease of these parameters. The biggest difference (12\% increases) arises from changing the FC penalties for unloaded cross roof rackson highway driving conditions. The smallest difference ( $0.8 \%$ increase) occurs by changing FC penalties of loaded roof racks on non-highway driving. This difference arises because the VMT for vehicles with unloaded racks is $4 \sim 8$ times higher than that of vehicles with loaded racks. Hence, a change in theFC penalty for vehicles with unloaded 
racks will be applied to more VMT and result in higher FC penalties. Note that no sensitivity analysis was conducted for unloaded roof rack FC impact on urban roadsbecause both consumer-reported data and on-road test data support our original assumption. For rack usage parameters, increasing unloaded weekday rack usage by $20 \%$ causes the highest percentage change $(9.6 \%)$ whereas the minimum change $(2.7 \%)$ is obtained by increasing loaded roof rack usage on weekends. This result can be explained by the fact that the 5 weekdays account for over $70 \%$ of total VMT. In summary, the most influential parameters are related to unloaded roof rack FC penalties and weekday usage patterns. These results suggest thatsome fuel-saving policies should focus on reducing the number of vehicles driving with empty racks.

\section{[Insert Figure 5 here]}

Another aspect of uncertainty lies on the distance traveledby vehicles with roof racks. Studies have shown that people who like outdoor activities travel more (Clawson and Knetsch, 2013). It is likely that people who install roof racks on their vehicles are outdoor-oriented as well. Hence, the average VMT for vehicleswith racksare higher than vehicles without racks. To assess the uncertainty of the VMT input parameter, we assume vehicles with racks have $5 \% \sim 20 \%$ higher VMT than normal vehicles. There are two ways of implementing these assumptions in the model. One way is to change the VMT mix but keep the LDV fleet total VMT unchanged. Another way is to increase the total LDV fleet VMT by increasing the VMT of vehicles with racks but keeping the VMT of normal vehicles unchanged. Increasing the VMTs 5\% 20\% for vehicles with racks leads to a $0.008 \% \sim 0.03 \%$ increase in roof rack FC penalties relative to total transportation $\mathrm{FC}$. The second approach, increasing LDV fleet total VMT, increases penalties $0.04 \%$ o. $15 \%$. Either way, the overall impact is negligible. 


\subsection{Impacts of Future Government Polices and Changes inConsumer Behavior}

We conductedadditional analyses to evaluate the impacts ofgovernment policies or changes consumerbehavior. In the earlier analyses, we assumed constant rack FC penalty and usage parameters until 2040 (see Table 1). But here wechange the parametersto examine impacts of various policies.

As the US economy continues growing and more people participate in outdoor activities, both sales and usage of roof racks will increase (The Reynolds and Reynolds Company, 2014). The US Travel Association projected that domestic personal travel expenditure in US will increase by 53\% from 2011 to 2020, equivalent to 4.3\% average annual growth rate (US Travel Association, 2015). By applying the same growth rate, the usage of roof racks will increase by about $200 \%$ by 2040 . We call this scenario "More Travel". This scenario is a reasonable benchmark value to estimate future roof rack FC penalties even if the increases in actual rack usage do not perfectly track domestic travel expenditures.

Government policies might be enacted to assist consumers in the purchase and operation of roof racks. For example, energy labels (such as those for air conditioners and light bulbs (Olofsson, et al., 2004)) could help consumers understand the extra fuel costs resulting from using roof racks and nudge consumers towards the most aerodynamically efficient units. Energy labeling programs for appliances are typically inexpensive to implement and often stimulate significant market transformations. These policies may also encourage manufacturers toproducemore efficient racks to avoid being identified with selling a low-quality product. We examined the impact of a policy that caused more aerodynamic roof racks to be marketed and purchased. We modeled this as a gradual reduction of roof rack vehicle FC penalties by $50 \%$ by 2040 . This seems easily achievable 
given the wide range in efficiencies of current models. We call this scenario "ImprovedEff. Roof Rack".

Other policies might facilitate installation and removal of racks so that vehicle owners will remove them when not actually transporting bicycles, skis, and other goods. The extreme policy would be a prohibition of driving with empty racks, which would be both unrealistic and difficult to enforce. We modeled this policy asgradually reducing driving with unloaded cross roof racks on both highway and non-highway roads to $0 \%$ by year 2040 , and call this scenario as "Banned Unloaded RR".We also examined other scenarios by combining any of two or three of the defined three scenarios. A summary of the scenarios and their descriptions are shown in Table 1.

[Insert Table 1here]

Thescenario "Improved Eff. RR + Banned Unloaded RR" leads to the lowest FC penalties arising from roof rack usage. Compared with the base case scenario, a total of 200 million GGE can be saved during the model timeframe of 2015 to 2040. In addition, compared with worst scenario "More Travel", "ImprovedEff. RR + Banned Unloaded RR" has potential cumulative savingsof1.2billion GGE over the 26 years. "Banned Unloaded RR" achieves the second highest reduction in the roof rack FC penalty, followed by the case "Improved Eff. RR". The scenarios again confirm that reducing usage of unloaded roof racks will save more fuelcompared with improving roof rack energy efficiency, but only if a successful policy to radically transform driver behavior can be implemented. In summary, if no policies are launched to improve aerodynamic efficiency of racks and to reduce driving with empty racks, we can expect increasing fuel consumption caused by roof racks. 
[Insert Figure 6 here]

\subsection{Discussion}

The additional fuel usearising from use of roof racksisuncertain because an estimate requires information about the number of racks in actual use as well as the FC penalty at the single-vehicle level. To overcome the data gaps, we usednovelsources for data collection, such as online forums and crowd-sourcing (Amazon Mechanical Turk). Our observations show that $3.0 \%$ and 2.5\% of vehicles are being driven with empty roof racks during weekdays and weekends, respectively. Only $0.5 \%$ and $0.9 \%$ of the vehicles have loaded rackson weekdays and weekends, respectively. Loaded racks were observed more often duringweekends, presumably because more people carry recreational equipment for leisure use on weekends. The noveldata collection techniques used in this analysis have potential applications in other situations where national surveys are required. Amazon Mechanical Turk is especially intriguing because it enables surveys to be performed around the country quickly and at low costs.

We find consistent estimates of FC penalties across laboratory tests, on-road tests,andconsumer-reported data. Depending on the roof rack configuration (unloaded or loaded cross roof rack) and driving condition (highway or urban roads), a roof rack can increase a passenger car's fuel consumption $0 \% \sim 25 \%$ and a passenger truck's consumption and $0 \% \sim 11.7 \%$.

Based on our modeling results, roof racks are responsible for an additional 90 107million GGEper yearbetween 2015 and 2040, which are about $0.78 \% \sim 0.84 \%$ of LDVfleet FC.Sensitivity analyses on input parameters indicate that parameters related to usage (particularly unloaded cross roof rack usage on weekdays)most strongly affect total fuel penalties. This finding clearly points out that 
policies seeking to reduce fuel consumption from roof racks should focus on vehicles being driven with unloaded racks on weekdays, although it's not clear how these behavior changes would be-or could be-implemented. On the other hand, the results do not significantly change if vehicles with roof rack are driven more than average vehicles.

\section{Conclusion and Policy Implications}

This is the first attempt to quantitatively and systematically evaluate national FC penalties of roof racks. It is important to assess the additional FC caused by the usage of roof racks because they are one of the most popular add-on components in the U.S. automobile market.Our results show that roof racksare responsible for $0.78 \%$ to $0.84 \%$ of US transportation FC in the next two decades. However, the absolute fuel penalty will decline from 107 million to 90 million GGE from 2015 to 2040 as more energy efficient vehicles penetrate the market. Sensitivity analyses demonstrated the robustness of these results. Our proposed framework can also quantify FC impacts of other after-market automobile components.

Roof racks raise national fuel consumption by only about 1\%, which is about 100 million GGE per year. It is useful to put this $1 \%$ in context of other national policies. Fuel cell electric vehicles and battery electric vehicles have received considerable federal attention and support. For comparison, the additional fuel consumption caused by roof racks is about 6 times larger than anticipated fuel savings from fuel cell vehicles and $40 \%$ of anticipated fuel savings from battery electric vehicles in $2040^{3}$. In addition, the FC penalty is easily detected by all drivers with roof racks. Government policies could address this issue. For example, energy labels could guide consumers towards the

\footnotetext{
${ }^{3}$ AEO 2015 reference case projected 1.07 million and 0.06 million battery electric vehicles and fuel cell electric vehicles existing in the vehicle stock in United States. Assuming average annual VMT is 13350 miles (Stephens, 2014) and average fuel economy of conventional gasoline vehicles fleet is 52 MPG (EIA, 2015), the fuel savings achieved by battery cell electric vehicles and fuel cell electric vehiclesare259 million and 15 million GGE respectively.
} 
most aerodynamic racks and encourage manufacturers to improve efficiencies of their products.

Additional policies could facilitate, or even mandate, removal of racks when they are not actually in use. Anticipated growth in rack usage makes such policies even more important. We createdscenarios covering possible outcomes from implementing these policies as well as a possible increase in future use.The combined strategy ofaerodynamic improvementsand eliminating driving with empty (unloaded) racks will achieve the lowest roof rack FC penalty. Acumulative saving of 1.2 billion GGE can be saved compared with the base case over the next 25 years. Eliminating unloaded cross roof racks is a more effective strategy, compared with increasing the energy efficiency of roof racks, because vehicles with unloaded cross roof racks account for $4 \sim 8$ times more VMT (hence, more fuel consumption)than vehicles with loaded racks. From a practical perspective, however, improving the aerodynamics of new racks may be simpler to accomplish than changing behavior.

\section{Acknowledgments}

YC was supported by the U.S. Department of Energy under Contract No. DE-AC36-08GO28308 with the National Renewable Energy Laboratory. AM was supported by the U.S. Department of Energy under Contract No. DE-AC02-05CH11231. The authors would like to thank the three anonymous reviewers' comments and suggestions. 


\section{REFERENCES}

Al-Alawi, B.M., Bradley, T.H., 2014. Analysis of corporate average fuel economy regulation compliance scenarios inclusive of plug in hybrid vehicles.Applied Energy, Vol.113, pp. 1323-1337.

Barter, G.E., Reichmuth, D., Westbrook, J., Malczynski, L.A., West, T., Manley, D.K., Guzman, K.D., Edwards., D.M., 2012. Parametric analysis of technology and policy tradeoffs for conventional and electric light-duty vehicles. Vol. 46, pp. 473-488.

Borken-Kleefeld, J., Chen, Y., 2015. New emission deterioration rates for gasoline cars Results from long-term measurements. Atmospheric Environment, Vol. 101, 58-64.

Bureau of Transportation Statistics, 2015. National Transportation Statistics, Table 4-23: Average Fuel Efficiency of U.S. Light Duty Vehicles.http://www.rita.dot.gov/bts/sites/rita.dot.gov.bts/files/publications/national transpor tation statistics/html/table 04 23.html Accessed on July 20th, 2015.

Carr, G., 1976. Reducing Fuel Consumption By Means of Aerodynamics ‘Add-On’ Devices. SAE Technical Paper, 760187, doi: 10.4271/760187.

Chen, Y., Borken-Kleefeld, J., 2014. Real-driving emissions from cars and light commercial vehicles - Results from 13 years remote sensing at Zurich/CH. Atmospheric Environment, Vol. 88, 157-164.

Chen, Y., Fan, Y., 2013. Transportation fuel portfolio design under evolving technology and regulation: A California case study. Transportation Research Part D: Transport and Environment, Vol. 24, pp. 76-82.

Chen, Y., Fan, Y., 2014. Coping with technology uncertainty in transportation fuel portfolio design. Transportation Research Part D: Transport and Environment, Vol. 32, pp. 354-361.

Chowdhury, H., Alam, F., Khan, I., Djamovski, V., Watkins, S., 2012. Impact of Vehicle Add-ons on Energy Consumption and Greenhouse Gas Emissions. Procedia Engineering, Vol. 49, pp. 294-302.

Clawson, M., Knetsch, J.L., 2013.Economics of Outdoor Recreation.RFF Forests, Lands, and Recreation Set, Volume 3 of Resources for the Future Library Collection.Forests, Lands. Routledge, London, UK.

Department of Energy. How Vehicles Are Tested. https://www.fueleconomy.gov/feg/how tested.shtml Accessed on July 1st, 2015.

U.S. Energy Information Administration, Assumptions to the Annual Energy Outlook 2015, Washington, DC http://www.eia.gov/forecasts/aeo.

Environmental Protection Agency, 2009.MOVES2010b User's Guide. Washington, D.C. 
Environmental Protection Agency, 2013. Light-duty automotive technology, carbon dioxide emissions, and fuel economy trends: 1975 through 2013.

http://www.epa.gov/fueleconomy/fetrends/1975-2013/420r13011.pdf Accessed on July 10th, 2015.

Gao, Z., Curran, S.J., Parks II, J.E., Smith, D.E., Wagner, R.M., Daw, C.S., Edwards, k.d., Thomas, J.F., 2015. Drive cycle simulation of high efficiency combustions on fuel economy and exhaust properties in light duty vehicles. Applied Energy, Vol. 157, pp. 762-776.

Global Fuel Economy Initiative. Plan of Action 2012-2015. Geneva, Switzerland.

Goldberg, P.K., 1998. The effects of the corporate average fuel efficiency standards in the U.S. Journal of Ind Econ, Vol. 46, pp. 1-33.

Hansen, J.H., Blakenship, J.L., 1986. Highway Patrol Light Bar Effects on Vehicle Fuel Efficiency. Transportation Research Record, Journal of the Transportation Research Board, Transportation Research Board of the National Academies, Vol. 1059, pp. 53-56.

Howard, G., 1986. Automobile aerodynamics: theory and practice for road and track. Osprey.

Hucho, W.H. Aerodynamics of Road Vehicles: From Fluid Mechanics to Vehicle Engineering. $4^{\text {th }}$ ed. Society of Automotive Engineers Inc. February 1998.

Hughes, P., 1991. The role of passenger transport in $\mathrm{CO}_{2}$ reduction strategies. Energy Policy, Vol. 19(2), pp. 149-160.

International Energy Agency, 2009.Transport, Energy and $\mathrm{CO}_{2}$. Paris, France.

Jawad, B., Perez, J., Bachler, J., Cramb, R., et al., 2000.An innovative bicycle roof rack using sliding rail technology. SAE Technical Paper, 2000-01-3089, doi: 10.4271/2000-01-3089.

Juhala, M., 2014. Improving vehicle rolling resistance and aerodynamics, In Alternative Fuels and Advanced Vehicle Technology for Improved Environmental Performance, edited by Richard Folkson, Woodhead Publishing, Page 462-475.

Karbon, K., Dietschi, U., 2005. Computational analysis and design to minimize vehicle roof rack wind noise. SAE Technical Paper 2005-01-0602, DOI: 10.4271/2005-06-02.

Kelly, K., Holcombe, H., 1964. Aerodynamics for Body Engineers. SAE Technical Paper 640050, doi: 10.4271/640050.

Kirby E.G., 2015.An evaluation of the effectiveness of US CAFE Policy.Energy Policy, Vol. 23, pp. 107-109. 
Kyle P., Kim, S.H., 2011. Long-term implications of alternative light-duty vehicle technologies for global greenhouse gas emissions and primary energy demands. Energy Policy, Vol. 39 (5), pp. 3012-3024.

Lee, M., Lee, J., Kim, D., 2002.Reduction of Aeolian noise from roof rack crossbars using asymmetric cross-section geometry. SAE Technical Paper, 2002-01-1275, doi: 10.4271/2002-01-1275.

Leighty, W., Ogden, J.M., Yang, C., 2012. Modeling transitions in the California light-duty vehicles sector to achieve deep reductions in transportation greenhouse gas emissions. Energy Policy, Vol. 44, pp. 52-67.

Lenner, M. Influence of Roof-Rack, Trailer Etc. On Automobile Fuel Consumption and Exhaust Emissions, Measured On-The-Road. SAE Technical Paper,1998-0682, doi: $10.4271 / 980682$.

Mandadapu, S., Chinta, B., Jutila, B., Schoenefeld, M., 2011.Robust Design of a light weight flush mount roof rack. SAE Technical Paper, 2011-01-1274, doi: 10.4271/2011-01-1274.

Morrison, G.M., Chen, Y., 2011. How will changes in the ethanol market affect California's Low Carbon Fuel Standard? Transportation Research Record: Journal of the Transportation Research Board, Transportation Research Board of the National Academies, Vol. 2252, pp. 16-22.

Oak Ridge National Laboratory, 2014. Transportation Energy Data Book, $33^{\text {rd }}$ edition. U.S. Department of Energy, July 2014.

Olofsson, T., Meier, A., Lamberts, R., 2004.Rating the energy performance of buildings."The International Journal of Low Energy and Sustainable Buildings, Vol. 3.

Raub, R.A., 1985. Removal of Roof-Mounted Emergency Lighting from Police Patrol Vehicles: An Evaluation. Transportation Research Record, Journal of the Transportation Research Board, Transportation Research Board of the National Academies, Vol. 1047, pp. 83-88.

Roof racks. Digital image. Thule Group .

Website, accessed on December $1^{\text {st }}, 2015$.

$<\mathrm{http}$ :/www.thulegroup.com/en?utm_source=thule.com\&utm_medium=referral\&utm_campaign $=$ ThuleGroup $>$

Senthooran, S., Duncan, B., Freed, D., Hendriana, D., et al., 2007. Design of roof-rackcrossbars for production automobiles to reduce howl noise using a Lattice Boltzmann Scheme. SAE Technical Paper, 2007-01-2398, doi: 10.4271/2007-01-2398.

Stephens, T.S., Birky, A.K., Ward, J., 2014. Vehicle Technologies Program Government Performance and Results Act (GPRA) Report for Fiscal Year 2015. Report No. ANL/ESD-14/3.Argonne National Laboratory. 
The Reynolds and Reynolds Company, 2014.AddOnAuto: Auto Accessories Sales Mid-Year Trend Report. October, 2014.

Thomas, J., Huff, S., West, B., 2014.Fuel Economy and Emissions Effects of Low Tire Pressure, Open Windows, Roof Top and Hitch-mounted Cargo, and Trailer.SAE Int. J. Passeng. Cars - Mech. Syst. 7(2), pp. 862-872.

Wang, H., Fu, L., Lin, X., Zhou, Y., Chen, J., 2009. A bottom-up methodology to estimate vehicle emissions for the Beijing urban area.Science of the total environment, Vol. 407(6), pp. 1947-1953.

U.S. Environmental Protection Agency, 2013.1970-2013 Average annual emissions, all criteria pollutants in MS Excel, 2013.National Emissions Inventory Air Pollutant Emissions Trends Data.http://www.epa.gov/ttn/chief/trends/index.html (accessed May $15,2014)$.

US Environmental Protection Agency, 2006.Final TechnicalSupport Document Fuel Economy Labeling of Motor VehicleRevisions to Improve Calculations of Fuel Economy Estimates,EPA420-R-06-017, December 2006.

U.S. Travel Association, 2015.2011-2020 Peronal and Business Travel Industry Forecasting in United States.https:/www.ustravel.org/sites/default/files/page/2010/12/ForecastSummary.pdf Accessed on Nov. 30th, 2015.

Westbrook, J., Barter, G.E., Manley, D.K., West, T.H., 2014. A parametric analysis of future ethanol use in the light-duty transportation sector: Can the US meet its Renewable Fuel Standard goals without an enforcement mechanism? Vol. 65, pp. 419-431.

Whispbar, 2011."Whispbar - The Quietest Removable Roof Racks and Rack Accessories for The Great Outdoors." http://www.whispbar.com/.

Wu, D., Aliprantis, D.C., 2013.Modeling light-duty plug-in electric vehicles for national energy and transportation planning. Energy Policy, Vol. 63, pp. 419-432. 
Table 1. Scenario dues to different government policies and consumer behaviors

\begin{tabular}{|c|c|c|c|}
\hline & RR Veh. Level FC* & Loaded RR Usage* & Unloaded RR Usage* \\
\hline Base Case* & $\begin{array}{l}\text { PC: } \\
\text { Highway-Unload RR: } 8 \% \\
\text { Highway-Loaded RR: } 24.8 \% \\
\text { Nonhighway-Unloaded RR: } 0 \% \\
\text { Nonhighway-Loaded RR: } 1.1 \% \\
\text { PT: } \\
\text { Highway-Unload RR: } 2.4 \% \\
\text { Highway-Loaded RR: } 11.7 \% \\
\text { Nonhighway-Unloaded RR: } 0 \% \\
\text { Nonhighway-Loaded RR: } 0.5 \%\end{array}$ & $\begin{array}{l}\text { Weekday: } 0.5 \% \\
\text { Weekend: } 0.9 \%\end{array}$ & $\begin{array}{l}\text { Weekday: } 3.0 \% \\
\text { Weekend: } 2.5 \%\end{array}$ \\
\hline More Travel & No change & $\begin{array}{l}\text { Gradually doubled } \\
\text { from } 2015 \text { to } 2040\end{array}$ & $\begin{array}{l}\text { Gradually doubled } \\
\text { from } 2015 \text { to } 2040\end{array}$ \\
\hline Improved Eff. RR & $\begin{array}{l}\text { Gradually reduced by } 50 \% \\
\text { from } 2015 \text { to } 2040\end{array}$ & No change & No change \\
\hline Banned unloaded RR & No change & No change & $\begin{array}{l}\text { Gradually eliminated } \\
\text { from } 2015 \text { to } 2040\end{array}$ \\
\hline $\begin{array}{l}\text { More Travel + } \\
\text { Improved Eff. RR }\end{array}$ & $\begin{array}{l}\text { Gradually reduced by } 50 \% \\
\text { from } 2015 \text { to } 2040\end{array}$ & $\begin{array}{l}\text { Gradually doubled } \\
\text { from } 2015 \text { to } 2040\end{array}$ & $\begin{array}{l}\text { Doubled from } 2015 \text { to } \\
2040\end{array}$ \\
\hline $\begin{array}{l}\text { More Travel }+ \\
\text { Banned unloaded RR }\end{array}$ & No change & $\begin{array}{l}\text { Gradually doubled } \\
\text { from } 2015 \text { to } 2040\end{array}$ & $\begin{array}{l}\text { Gradually eliminated } \\
\text { from } 2015 \text { to } 2040\end{array}$ \\
\hline $\begin{array}{l}\text { Improved Eff. RR + } \\
\text { Banned Unloaded } \\
\text { RR }\end{array}$ & $\begin{array}{l}\text { Gradually reduced by } 50 \% \\
\text { from } 2015 \text { to } 2040\end{array}$ & No change & $\begin{array}{l}\text { Gradually reduced to } \\
0 \% \text { from } 2015 \text { to } 2040\end{array}$ \\
\hline All three & $\begin{array}{l}\text { Gradually reduced by } 50 \% \\
\text { from } 2015 \text { to } 2040\end{array}$ & $\begin{array}{l}\text { Gradually doubled } \\
\text { from } 2015 \text { to } 2040\end{array}$ & $\begin{array}{l}\text { Gradually eliminated } \\
\text { from } 2015 \text { to } 2040\end{array}$ \\
\hline
\end{tabular}

*Unless specified, parameters defined in scenarios remain the same for all analysis years, 2014 to 2040. 

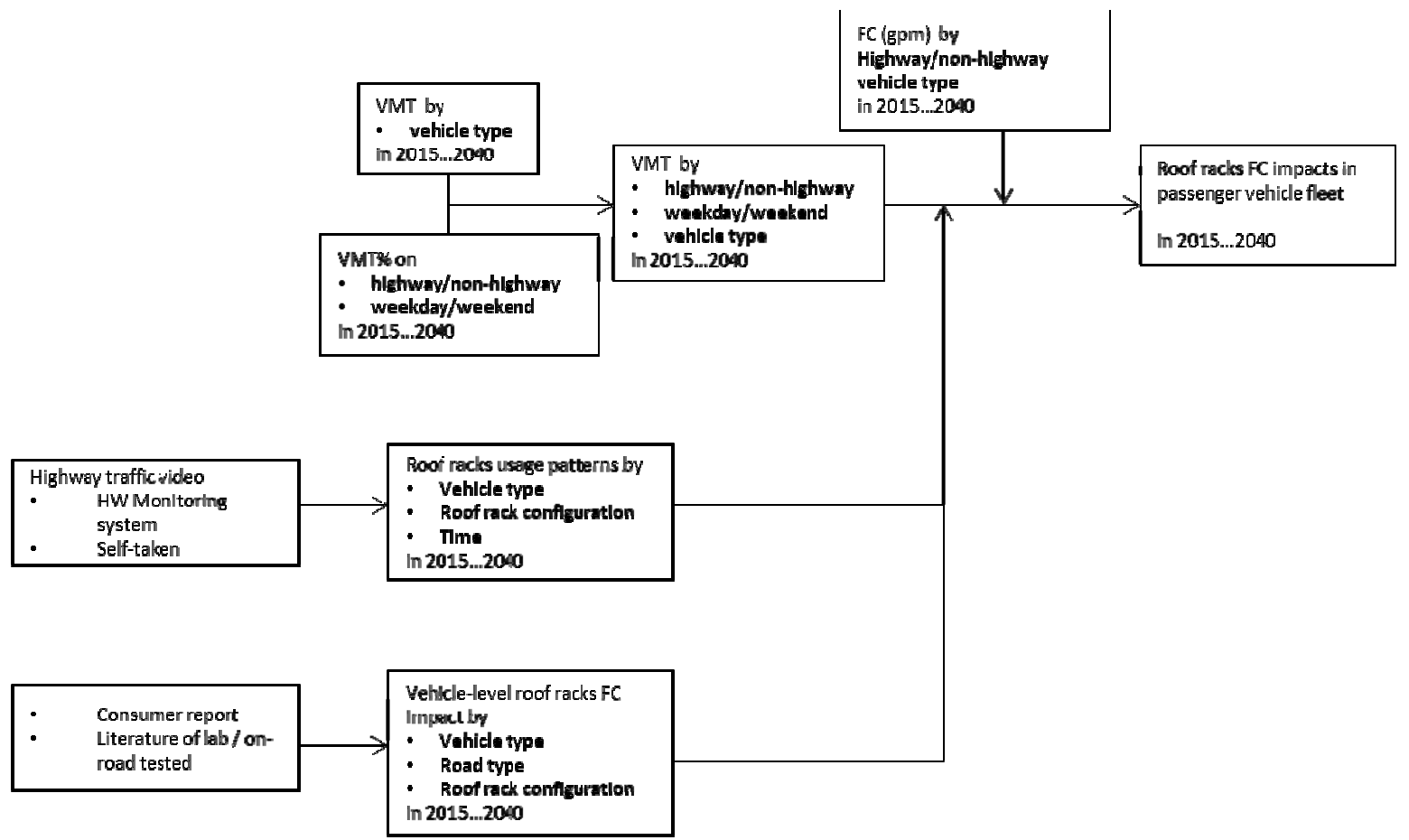

Figure 1.Framework for estimating nationwide fuel penalty caused by passenger vehicle roof racks.

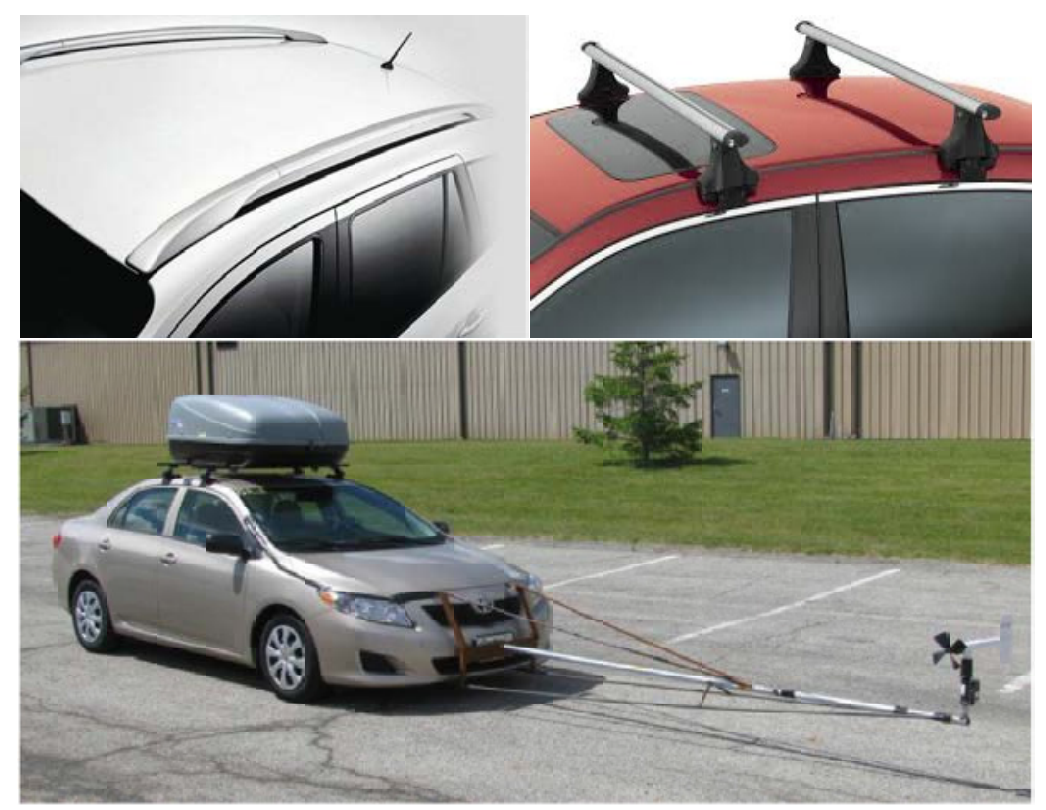

Figure 2. Examples of different roof rack configurations. Upper left: Roof with built-in rails (from Thule); Upper right: Unloaded cross roof rack (from Thule); Lower: Loaded cross roof rack (Thomas et al., 2014). 


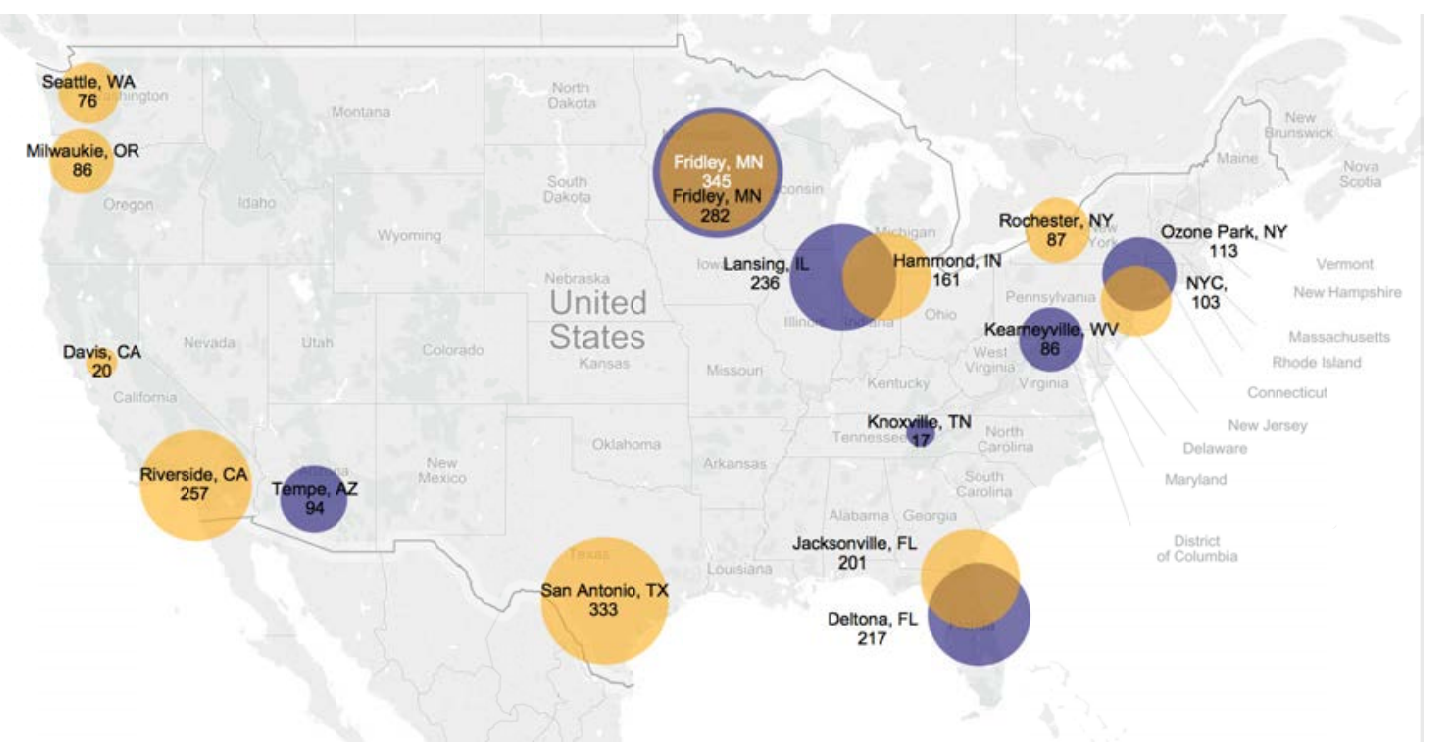

Figure 3.Video Survey Sampling Locations and Number of Observations.

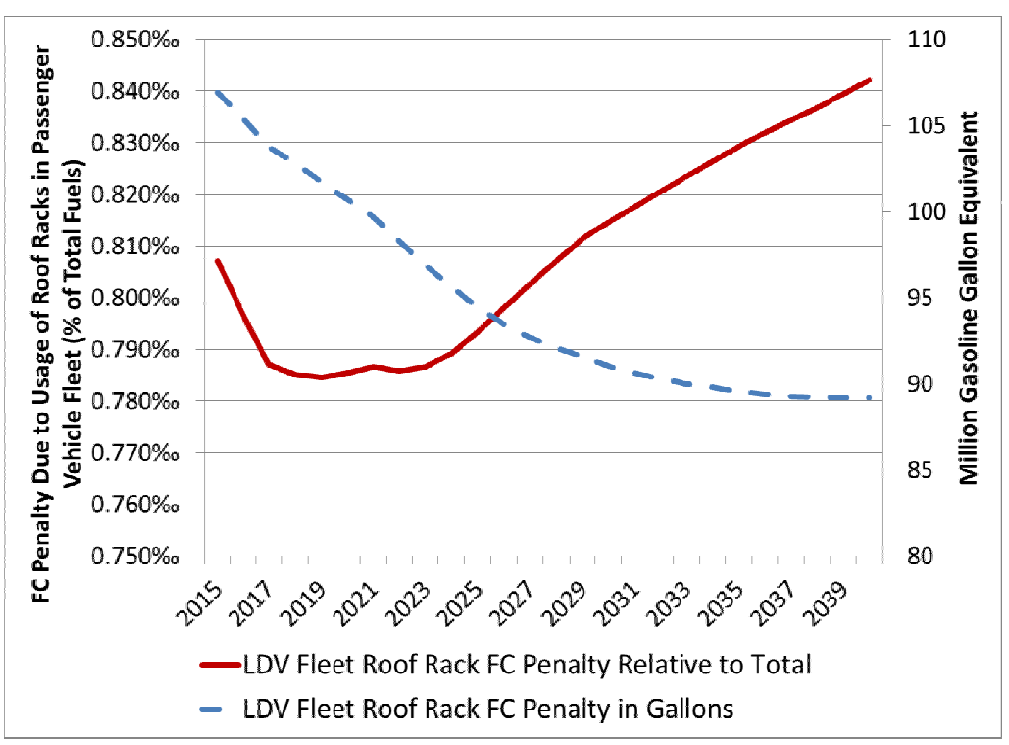

Figure 4. Roof Rack FC Penalty Relative to Total LDV Fleet FC (left axis) and in GGE (right axis) 


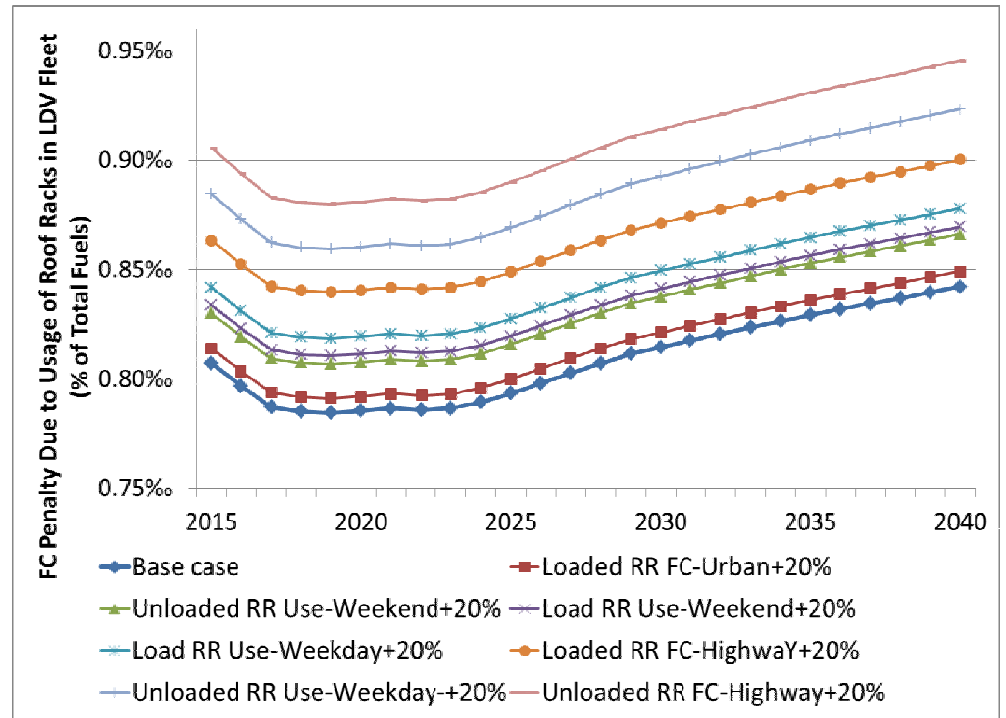

Figure 5.Sensitivity of Input Parameters to Roof Rack FC Penalty.

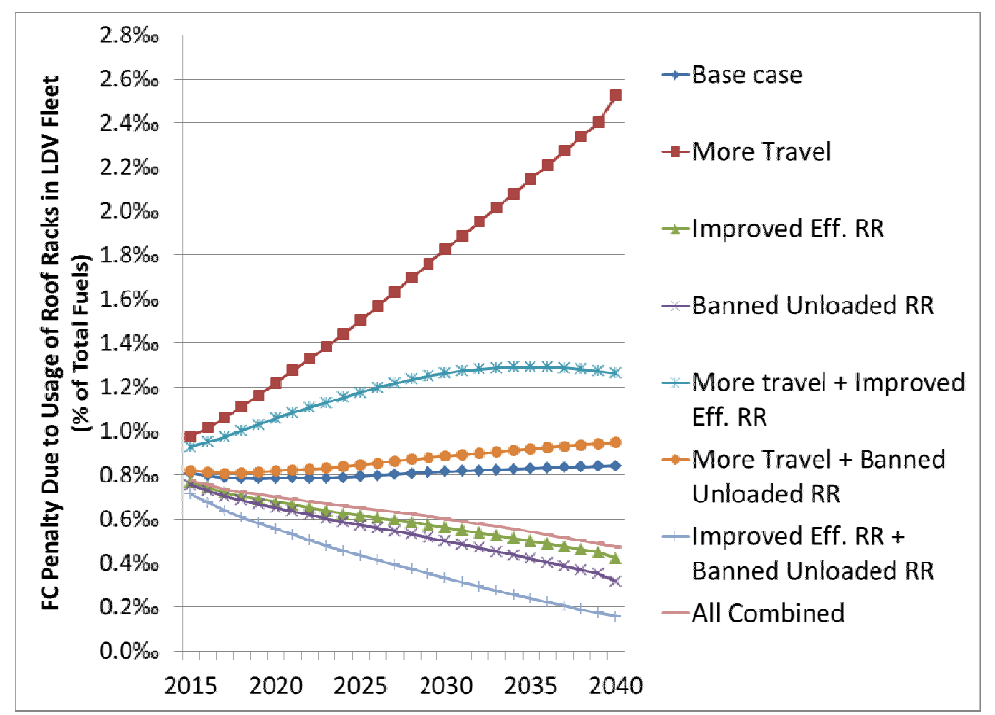

Figure 6.Results under Various Government Policies and Consumer Behavior Scenarios. 